\title{
Khawâdjâ 'Abd Allâh ANSÂRÎ, Cris du Cœur, Munâjât
}

Trad., prés. et annot. par Serge Laugier de Beaurecueil, préf. de Amir Mohammad Ali Moezzi. Paris, Éditions du Cerf, coll. «Patrimoines Islam», 2010, $177 \mathrm{p}$.

\section{Mostafa Zekri}

\section{(2) OpenEdition}

1 Journals

\section{Édition électronique}

URL : http://journals.openedition.org/assr/22863

DOI : $10.4000 /$ assr.22863

ISSN : $1777-5825$

Éditeur

Éditions de l'EHESS

\section{Édition imprimée}

Date de publication : 31 décembre 2011

Pagination : 94

ISBN : 9782713223273

ISSN : 0335-5985

Référence électronique

Mostafa Zekri, "Khawâdjâ 'Abd Allâh ANSÂRî, Cris du Cœur, Munâjât », Archives de sciences sociales des religions [En ligne], 156 | octobre-décembre 2011, document 156-6, mis en ligne le 14 février 2012, consulté le 21 septembre 2020. URL : http://journals.openedition.org/assr/22863 ; DOI : https:// doi.org/10.4000/assr.22863

Ce document a été généré automatiquement le 21 septembre 2020.

(c) Archives de sciences sociales des religions 


\section{Khawâdjâ 'Abd Allâh ANSÂRÎ, Cris du Cœur, Munâjât}

Trad., prés. et annot. par Serge Laugier de Beaurecueil, préf. de Amir Mohammad Ali Moezzi. Paris, Éditions du Cerf, coll. «Patrimoines Islam», 2010, 177 p.

Mostafa Zekri

\section{RÉFÉRENCE}

Khawâdjâ 'Abd Allâh ANsÂRî, Cris du Cœur, Munâjât,Trad., prés. et annot. par Serge Laugier de Beaurecueil, préf. de Amir Mohammad Ali Moezzi. Paris, Éditions du Cerf, coll. «Patrimoines Islam», 2010, 177 p.

Cris du cœur est l'expression que le Père dominicain Serge de Beaurecueil (1917-2005) a choisie pour traduire du persan les Munājāt (Monājāt-Nāmeh) de Khawâdjâ 'Abd Allâh Ansârî (1006-1089). Dans un article, publié peu de temps avant la présente édition: «The Invocation of Saints and/or Spirits by the Sufis and the Shamans: About the Munâjât Literary Genre in Central Asia» (Kyoto Bulletin of Islamic Area Studies, 1-1, 2007), Thierry Zarcone analyse les munājāt en général en tant que genre littéraire pratiqué en Asie Centrale. Il évoque dans son étude les Munājāt d'al-Ansârî ainsi que la traduction de Serge de Beaurecueil, et mentionne d'autres propositions de traduction du terme munājāt, notamment celle de Carl W. Ernst (conversation intime avec Dieu) et de Van den Berg (prières improvisées).

Les Éditions du Cerf ont repris scrupuleusement, comme le souligne l'éditeur lui-même, la traduction déjà publiée par Beaurecueil chez Sindbad, en 1988. Celle-ci est enrichie dans la présente édition d'une préface (p.9-17) d'Amir Mohammad Ali Moezzi qui met l'accent sur l'importance de la langue persane, sa sacralité et sa capacité d'exprimer «les subtilités et les profondeurs des expériences et sentiments proprement religieux» (p.10). Le préfacier évoque, sans forcer les détails, l'apport de quelques grands savants, philosophes ou poètes iraniens tels Fakhr al-Dîn al-Râzî, al-Isfahânî, al-Suhrawardî, Ibn 
Sînâ, Mustamlî Bukhârî, Hujwîrî, 'Umar Khayyâm ou encore al-Ghazalî. Après une brève mention des controverses et des discussions relatives à la question de la suprématie des Arabes sur les peuples conquis et la supériorité de leur langue sur les autres, Amir Moezzi évoque quelques traditions attribuées au Prophète et à Ja'far al-Sâdiq, et une fatwa de l'imâm Abû Hanîfa (m. 767) qui vantent les vertus des Persans.

Vient ensuite le texte de présentation des Munâjât, divisé en quatre parties. Serge de Beaurecueil commence par un aperçu biographique sur al-Ansârî (p.21-28) avant d'exposer les raisons du choix de traduire munājāt par Cris du cœur et les problèmes d'authenticité que posent les divers recueils de munājāt. Le traducteur a laissé, dit-il, «délibéremment de côté tous les recueils de Munâjât» et s'est limité à traduire les munājāt proprement dites (qui sont adressées directement à Dieu) contenues dans Tabaqāt al-Súfiyya, un ouvrage dicté par al-Ansârî à ses disciples vers la fin de sa vie, et le Kašf al-asrār de Rashîd al-Dîn Maybûdî (p.30). Dans les deux dernières parties de sa présentation, le Père de Beaurecueil choisit de parler distinctement des «images» et des «pensées» contenues dans le texte de munājāt. On peut, semble-t-il, se passer de cette distinction puisqu'il s'agit en fait d'une seule et même chose: «l'expérience intérieure». On peut également regretter le choix du titre de la dernière partie de cette présentation (La pensée). Ne s'agit-il pas, dans chaque munājāàt, d'un «cri du cœur» qui s'efforce de transmettre "une expérience spirituelle inexprimable» de celui qui est en quête de Dieu dans l'espoir de Le trouver. "Le chercheur ressemble à l'aveugle, qui poursuit la lumière dont il est entouré, ou au fou qui réclame un flambeau afin d'apercevoir le jour... On ne peut Le connaître que grâce à Sa lumière; on ne peut Le chercher que grâce à Son pouvoir... C'est mentir que de prétendre exprimer la réalité de Sa découverte» (p.47-48). Les cent soixante-sept munājāt de la présente traduction s'ordonnent autour de cette thématique qui trouve dans le langage allégorique un moyen flexible pour exprimer l'indicible. La recherche de Dieu implique chez le chercheur le questionnement et l'attente. Chaque interrogation est un effort pour atteindre le but. Citons à cet égard cette munājāt $\left(n^{\circ} 28\right)$, qui a nourri la méditation de Serge de Beaurecueil jusqu'à son décès dans une clinique de Rouen:

4 «Comment aurais-je su que la souffrance est mère de la joie, et que sous une déception se cachent mille trésors?

5 Comment aurais-je su que le désir annonce la rencontre, et que sous la nuée de la Munificence, tout désespoir est impossible?

6 Comment aurais-je su que cet Ami est indulgent, au point que sont incalculables Sa grâce et Sa miséricorde pour le pécheur?

7 Comment aurais-je su que ce Dieu glorieux gâte à ce point Son serviteur, et que pour Ses amis Il a tant de tendresse?

8 Comment aurais-je su que ce que je cherchais était au sein de mon esprit, et que l'honneur de Ta rencontre était pour moi un don gratuit?» 